\title{
Exploring Explanations for Local Reductions in Teenage Pregnancy Rates in England: An Approach Using Qualitative Comparative Analysis
}

\section{Tim Blackman}

Faculty of Social Sciences, The Open University

E-mail: tim.blackman@open.ac.uk

Teenage pregnancy rates in the UK are high compared with many other countries but there is marked variation across local areas, including those with high deprivation. This study uses the method of Qualitative Comparative Analysis to identify conditions associated with the presence or absence of a narrowing gap in teenage pregnancy rates as measured by the differences between deprived local authority areas and the national average. A higher proportion of black and minority ethnic groups in the local population is found to be a sufficient although not necessary condition for narrowing to have occurred. Surprisingly, a good assessment of commissioning practice - combined with other conditions - was associated with areas where the gap has not been narrowing.

Keywords: Teenage pregnancies, England, Qualitative Comparative Analysis.

\section{Introduction}

The United Kingdom's high rate of teenage pregnancies compared to other Western European countries became a policy priority in the early 1990s (Department of Health, 1992). Its framing as a policy problem reflects concerns about the disadvantaged conditions predisposing teenagers to become parents, and the social disadvantage and heightened medical risks associated with teenage pregnancy and parenthood. In recent years, rates have been falling but with considerable local variation, prompting a government minister to comment that:

There remains a huge variation in the progress that has been made in reducing teenage pregnancy rates across the country. Some local authorities have seen their rates decline by up to 45 per cent while others have struggled. It is important, therefore, that local areas learn from each other and share what has worked, so that they invest in the things that will really make a difference. (Teather, 2011)

There is a strong association between deprivation and teenage childbearing, but marked local variation occurs even among areas with high deprivation (McCulloch, 2001; Bradshaw et al., 2005; Audit Commission, 2010). Other local conditions and differences in practices are therefore likely to be important explanations for this variation.

This article reports results from an analysis of data about strategies and contextual conditions at local authority level in England. The case-based method of Qualitative Comparative Analysis (QCA) is used to explore these data for possible causal pathways 
to different local teenage pregnancy rate outcomes. QCA is based on the systematic comparison of cases, with cases represented as configurations of conditions that form sets associated with an outcome. The method was developed for small-N studies of countries and organisations, originally in comparative politics and historical sociology, but can also be used with large micro-datasets (Ragin, 2000; Rihoux and Ragin, 2009). QCA uses the term 'condition' rather than variable, but a condition is in effect an explanatory variable. Explanations are combinatorial in nature and these combinations represent pathways to the outcome, with the causal argument based on substantive and theoretical reasoning.

\section{Methodological approach}

Combinatorial explanations are more likely to reflect actual complex realities than explanations derived from conventional statistical techniques such as multiple regression (Byrne, 1998, 2011). This is because these techniques are generally based on isolating the 'independent' effect of each variable while holding the other variables constant, an experimental rather than real scenario. Multiple regression also aims at a good fit of the model to all cases, but in an average sense that fails to account for the possible, indeed often likely, existence of alternative combinations that lead to the same outcome.

Although interaction terms can be included in regression models, they are extremely limited in coping with even three-way interactions, and the issue of averaging remains (Grofman and Schneider, 2009). There is also no means of distinguishing between necessary and sufficient causes, a key strength of QCA. QCA's combinatorial explanations are conjunctural, based on conditions coming together to produce an outcome and recognising that the effects of particular conditions may depend on the state of other conditions. It is therefore an especially apt method for exploring complexity and the possible causal pathways between an intervention and an outcome that include the effects of contextual conditions (Petticrew and Roberts, 2003; Petticrew et al., 2009).

QCA is a logical technique originally developed to work with 'crisp sets' of dichotomised conditions (crisp set QCA or csQCA). This is straightforward when a condition has only two values (such as male/female), but for continuous or categorical variables the researcher has to determine a threshold for binarisation (e.g. high/low). Binarisation also limits csQCA in terms of assessing the relative strength of effects. Recently new tools have extended QCA to address these issues and handle multi-value variables (fuzzy-set and multi-value QCA, or fsQCA and mvQCA).

The study reported in this article uses csQCA with dichotomised conditions. Although this inevitably means a loss of information, given that many of the original variables were categorical or continuous, it has two advantages compared to using multi-value variables. Firstly, the results can be used in 'truth tables', as shown later, that sort all the cases by their combinations of conditions, giving a very clear description of alternative causal pathways. Secondly, treating causes as non-scalar phenomena that either exist or not is useful for policy-making, since decision-makers often need to know whether or not a particular practice, strategy or contextual condition matters to whether an outcome happens (this can be compared to an odds ratio, for example, which can be very difficult to translate into practical decision-making).

An important consideration with csQCA, however, is how to decide on thresholds for binarising conditions measured on continuous or categorical scales. Sensitivity analysis can be undertaken to investigate the effects of different thresholds on the relationship 
with an outcome, but, as with other aspects of the method, this is ultimately a matter of interpretation, reflecting the 'qualitative' in QCA. The use of judgement is nevertheless based on transparent reasoning represented by explicit definitions and the use of a truth table; the absence of such transparency and systematic comparison is a weakness in much qualitative research (Rihoux and Ragin, 2009).

QCA starts with a need to define the cases, which is guided by the outcome of interest. For this study, the cases were twenty-seven of the seventy 'Spearhead' local authority areas in England that the last Labour government designated for targeted action to reduce health inequalities because of their high levels of deprivation and mortality (Department of Health, 2004). These areas are framed for the purpose of this study as local systems where three main organisational actors have worked together with the objective of reducing the area's teenage pregnancy rate: the NHS primary care trust that plans and commissions health services locally; one or more local authorities that run a range of services relevant to young people; and one or more multi-agency local strategic partnerships (LSPs) that are tasked with 'joining up' local services.

For each area a binary outcome was defined as the presence or absence of a narrowing gap between the area's teenage pregnancy rate and the national average over the period 2005 to 2009: 2005 was the year for which baseline assessments of conditions were made and 2009 was the most recent year for which teenage pregnancy rates for local authority areas were available at the time the data were analysed in 2011, allowing a four-year time lag between conditions in 2005 and outcomes in 2009. At baseline, the local rates varied from 38.1 to 85.0 conceptions per 1,000 females aged fifteen to seventeen. By the end of the period, they varied from 41.0 to 69.4. The national average was 41.4 at baseline and 40.2 at the end of the period. Data for each area are not presented here as a condition of NHS ethics approval was anonymity of areas and respondents (this was also to encourage candid responses to a self-assessment questionnaire). Assessment of the outcome trend for each local authority area was undertaken by two assessors based on a combination of approaches, including graphical visualisation and inspection and a calculation of the absolute and relative differences between 2005 and 2009. Although areas where the gap was not narrowing were predominantly those with lower rather than higher rates at baseline, there was no pattern among the areas with narrowing gaps, and including the baseline rate in the analysis did not contribute to explaining the outcome.

Conditions to be included in the analysis were selected by drawing on knowledge of the cases and the research literature. A 'long list' of possible causal conditions was compiled and then reduced to a shortlist for crisp set analysis using Ragin's (2008) fsQCA software (a confusing name for the software given that it can be used for crisp set analysis). This reduction was achieved in three ways: exploring the long list of variables (representing conditions) for relationships with the outcome using cross-tabulation in SPSS; consulting practitioners in a series of regional meetings about variables that did not display a bivariate relationship but were regarded as important in practice and therefore possibly having a role in combination; and testing the addition and substitution of variables in the QCA model to see whether cases not belonging to a configuration or having contradictory membership could be resolved (such as a 'narrowing' case belonging to a 'not narrowing' configuration).

Data about the long list of conditions in each Spearhead area were collected using structured self-assessment questionnaires and a range of secondary sources. 
Questionnaire design was informed by reviewing the academic and policy literatures (Exworthy and Powell, 2004; Department of Health, 2005a; Department of Health, 2005b; Asthana and Halliday, 2006; Blackman, 2006; Department for Education and Skills, 2006; Allen et al., 2007; Department for Communities and Local Government, 2007; Department of Health, 2007a; Department of Health, 2007b). A copy of the questionnaire is available at http://www.dur.ac.uk/spearheads.health/questionnaires.htm. The questions covered strategic level approaches and local conditions in the areas that could impact on progress with narrowing the teenage conceptions gap. Thus, the concern was with areawide strategies and characteristics rather than risk factors at an individual level (Allen et al., 2007). Conditions selected for analysis are described in Table 1.

All NHS primary care trusts, local authorities and LSPs in the Spearhead areas were invited to participate in the study. Those agreeing were asked to nominate a small team to complete the questionnaire, comprising the teenage pregnancy coordinator (a nationally defined role), a public health professional or local authority officer who had relevant responsibility and a sexual health lead professional from the NHS. Thirty-one out of seventy Spearhead areas returned the questionnaires, with complete returns from twentyseven. The response rate reflected a shortage of time in many areas to complete the exercise, but a Mann-Whitney test using the five variables that determine Spearhead status showed no significant difference between the areas participating in the study and the non-responding areas. In completing the questionnaires, teams were asked to adopt a whole system view across preventative and treatment services and NHS, local authority and voluntary services, and to justify their answers with examples and supporting documentation.

The secondary data included performance assessment ratings for both NHS primary care trusts and local authorities, deprivation scores, crime rates, a measure of local 'liveability' (Collinge et al., 2005), migration data, health services expenditure, the proportion of primary care practices classified as outliers on performance measures, the proportion of single handed practices, the number of general practitioners (GPs) per 100,000 population, a wide variety of educational attainment data and demographic data.

Practitioners were consulted at a series of workshops about the structure, content and phrasing of the questionnaires and the choice of secondary data. They were mainly public health professionals and local government officers. Following this feedback, the Department of Health's National Support Teams (NSTs) for teenage pregnancy and health inequalities provided further detailed comments.

The majority of the questions in the questionnaire used scales and the remainder had categories with some yes/no answers, so a series of judgements had to be made about binarisation. The secondary data comprised continuous or categorical variables. Thresholds for dichotomisation were based on where a change in relationship with the outcome occurred (for example, the 'narrowing' outcome was clustered in the lower range of scores on the index of multiple deprivation, which provided the basis for binarising the scores into higher and lower). Robustness checks were undertaken to determine how binarisation thresholds affected the findings, and the thresholds used were found to be robust. Out of the long list, only a relatively small number of conditions had any patterned relationship with the outcome indicators and it was possible to dichotomise them without much difficulty on the basis of clear breaks in the patterns. The relevant variables were then imported into the fsQCA software to explore their effects in combination. 
Table 1 Descriptors for conditions associated with narrowing gaps in teenage pregnancy rates

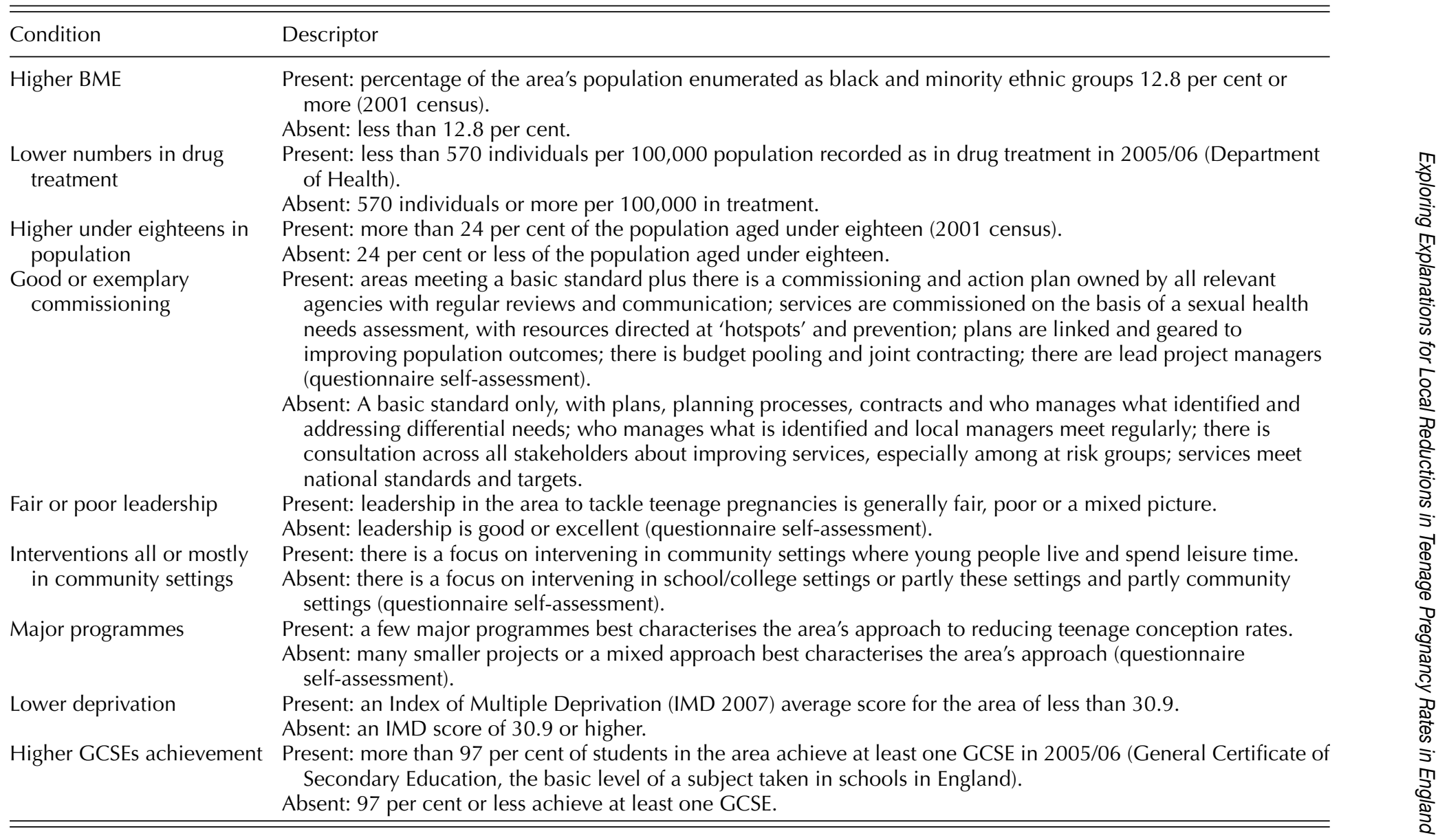


This software produces truth tables where each row represents a logical combination of conditions along with an outcome, all coded as binary ' $1 \mathrm{~s}^{\prime}$ or ' $0 \mathrm{~s}^{\prime}$ representing present or absent. Truth tables include all the logical combinations of the selected conditions. These can easily exceed the number of cases; in reality social phenomena are limited in their diversity and encompass only some of the possible combinations (Ragin, 2000).

QCA's Boolean approach enables simplification of the data into succinct statements. Thus, if two combinations differ on only one condition yet have the same outcome, then that condition is considered redundant and can be removed (for example, if both a + $\mathrm{b}+\mathrm{c}=\mathrm{x}$ and $\mathrm{a}+\mathrm{b}=\mathrm{x}$ then the cause of $\mathrm{x}$ is described by one statement, $\mathrm{a}+\mathrm{b}$ ) . This process of logical minimisation is conducted stepwise by the QCA software until no further reduction of Boolean expressions can be achieved and the data are captured in minimal statements of causal conditions.

\section{Findings}

Table 2 shows the truth table produced from the nine conditions along with the outcome. There are twenty-seven combinations, i.e. in this instance each case is a unique combination. The program produces 'complex', 'intermediate' and 'parsimonious' solutions with increasing Boolean reduction. For reasons of space, only the parsimonious solution for the twenty-seven cases is discussed here; it is the most interpretable and interesting. Five sets emerge. The first two of these are 'narrowing' configurations while the other three are 'not narrowing' configurations. These are shown in Table 3. The narrowing configurations are:

Configuration 1. Higher BME

Configuration 2. Lower drug treatment numbers * Higher under eighteens * Absence of good/exemplary commissioning

The not narrowing configurations are:

Configuration 3. Lower BME * Lower under eighteens

Configuration 4. Lower BME* Higher numbers in drug treatment

Configuration 5. Lower BME* Good/exemplary commissioning

The solutions are fully consistent and there are no contradictory cases. A fundamental part of the logical reasoning used with QCA is to look for necessary and sufficient causes. Ragin (2000) points out that this can often reveal the challenge involved in achieving a policy outcome because all the necessary conditions for that outcome need to be in place. Sometimes, though, the outcome may occur regardless of what policy-makers do. In configuration 1, we see what appears to be an instance of this: a higher proportion of BME groups in the local population is a single sufficient condition for a narrowing gap regardless of the state of other conditions. However configuration 2 shows that this condition is not necessary for the gap to narrow although, as discussed in the next section, interpretation of this configuration is not straightforward if the aim is to identify 'what works'. In configurations 3 to 5, we see that 'lower BME' appears to be a necessary condition for the gap not to narrow, but is not sufficient. Table 3 maps the pathways onto the twenty-seven cases. It cannot just be assumed that these pathways are causal: each presents an explanandum to which to apply substantive and theoretical knowledge about what might be happening. 
Table 2 QCA 'truth table' output of conditions and their associations with teenage pregnancy rate outcomes $(1=$ present; $0=$ absent $)$

\begin{tabular}{|c|c|c|c|c|c|c|c|c|c|c|}
\hline Case & $\begin{array}{l}\text { Lower } \\
\text { deprivation }\end{array}$ & $\begin{array}{l}\text { Lower numbers in } \\
\text { drug treatment }\end{array}$ & $\begin{array}{l}\text { Higher } \% \text { under } \\
18 \mathrm{~s} \text { in population }\end{array}$ & $\begin{array}{l}\text { Higher GCSE } \\
\text { achievement }\end{array}$ & $\begin{array}{l}\text { Fair, poor or } \\
\text { mixed } \\
\text { leadership }\end{array}$ & $\begin{array}{l}\text { Interventions } \\
\text { all or mostly } \\
\text { in community } \\
\text { settings }\end{array}$ & $\begin{array}{l}\text { Higher BMEs } \\
\text { in population }\end{array}$ & $\begin{array}{l}\text { Major } \\
\text { programmes }\end{array}$ & $\begin{array}{l}\text { Basic standard of } \\
\text { commissioning }\end{array}$ & $\begin{array}{l}\text { Narrowing } \\
\text { gap }\end{array}$ \\
\hline 1 & 1 & 1 & 1 & 1 & 1 & 1 & 1 & 1 & 1 & 1 \\
\hline 2 & 1 & 1 & 1 & 1 & 1 & 0 & 0 & 0 & 1 & 1 \\
\hline 3 & 1 & 1 & 1 & 0 & 1 & 1 & 0 & 1 & 1 & 1 \\
\hline 4 & 0 & 1 & 0 & 0 & 1 & 1 & 1 & 0 & 1 & 1 \\
\hline 5 & 0 & 1 & 0 & 0 & 1 & 0 & 1 & 0 & 1 & 1 \\
\hline 6 & 0 & 0 & 1 & 0 & 0 & 0 & 1 & 0 & 0 & 1 \\
\hline 7 & 1 & 0 & 1 & 1 & 0 & 1 & 1 & 1 & 0 & 1 \\
\hline 8 & 0 & 0 & 1 & 0 & 1 & 0 & 1 & 0 & 1 & 1 \\
\hline 9 & 0 & 1 & 0 & 1 & 1 & 0 & 1 & 1 & 1 & 1 \\
\hline 10 & 0 & 1 & 1 & 0 & 1 & 1 & 0 & 1 & 1 & 1 \\
\hline 11 & 0 & 1 & 0 & 0 & 1 & 1 & 1 & 1 & 0 & 1 \\
\hline 12 & 1 & 1 & 0 & 0 & 0 & 0 & 0 & 0 & 0 & 0 \\
\hline 13 & 1 & 1 & 0 & 1 & 1 & 1 & 0 & 0 & 1 & 0 \\
\hline 14 & 0 & 1 & 1 & 0 & 0 & 1 & 0 & 0 & 0 & 0 \\
\hline 15 & 1 & 1 & 0 & 1 & 0 & 0 & 0 & 0 & 0 & 0 \\
\hline 16 & 1 & 1 & 0 & 1 & 0 & 0 & 0 & 1 & 1 & 0 \\
\hline 17 & 0 & 1 & 0 & 1 & 0 & 0 & 0 & 0 & 0 & 0 \\
\hline 18 & 0 & 1 & 0 & 0 & 0 & 0 & 0 & 0 & 0 & 0 \\
\hline 19 & 1 & 0 & 0 & 1 & 1 & 1 & 0 & 0 & 1 & 0 \\
\hline 20 & 1 & 0 & 0 & 1 & 0 & 0 & 0 & 0 & 1 & 0 \\
\hline 21 & 1 & 0 & 0 & 1 & 0 & 1 & 0 & 0 & 0 & 0 \\
\hline 22 & 1 & 0 & 1 & 1 & 1 & 1 & 0 & 0 & 1 & 0 \\
\hline 23 & 1 & 1 & 0 & 0 & 1 & 0 & 0 & 1 & 0 & 0 \\
\hline 24 & 0 & 0 & 1 & 0 & 1 & 0 & 0 & 0 & 1 & 0 \\
\hline 25 & 0 & 0 & 0 & 1 & 0 & 0 & 0 & 0 & 1 & 0 \\
\hline 26 & 0 & 0 & 0 & 0 & 0 & 1 & 0 & 1 & 0 & 0 \\
\hline 27 & 0 & 0 & 0 & 0 & 1 & 0 & 0 & 0 & 1 & 0 \\
\hline
\end{tabular}


Table 3 Boolean minimisation of the truth table identifying five configurations ( $1=$ present; $0=$ absent)

\begin{tabular}{|c|c|c|c|c|c|c|c|c|c|c|}
\hline Configuration & $\begin{array}{l}\text { Higher } \\
\text { BMEs in } \\
\text { population }\end{array}$ & $\begin{array}{l}\text { Lower } \\
\text { numbers in } \\
\text { drug treatment }\end{array}$ & $\begin{array}{l}\text { Higher \% } \\
\text { under } 18 \mathrm{~s} \text { in } \\
\text { population }\end{array}$ & $\begin{array}{l}\text { Basic standard of } \\
\text { commissioning }\end{array}$ & $\begin{array}{l}\text { Fair, poor or } \\
\text { mixed leadership }\end{array}$ & $\begin{array}{l}\text { Interventions } \\
\text { all or mostly in } \\
\text { community } \\
\text { settings }\end{array}$ & $\begin{array}{l}\text { Major } \\
\text { programmes }\end{array}$ & $\begin{array}{l}\text { Lower } \\
\text { deprivation }\end{array}$ & $\begin{array}{l}\text { Higher GCSE } \\
\text { achievement }\end{array}$ & $\begin{array}{l}\text { Narrowing } \\
\text { gap }\end{array}$ \\
\hline \multirow[t]{8}{*}{1} & 1 & 1 & 1 & 1 & 1 & 1 & 1 & 1 & 1 & 1 \\
\hline & 1 & 0 & 1 & 0 & 0 & 0 & 0 & 0 & 0 & 1 \\
\hline & 1 & 0 & 1 & 0 & 0 & 1 & 1 & 1 & 1 & 1 \\
\hline & 1 & 0 & 1 & 1 & 1 & 0 & 0 & 0 & 0 & 1 \\
\hline & 1 & 1 & 0 & 1 & 1 & 1 & 0 & 0 & 0 & 1 \\
\hline & 1 & 1 & 0 & 1 & 1 & 0 & 0 & 0 & 0 & 1 \\
\hline & 1 & 1 & 0 & 1 & 1 & 0 & 1 & 0 & 1 & 1 \\
\hline & 1 & 1 & 0 & 0 & 1 & 1 & 1 & 0 & 0 & 1 \\
\hline \multirow[t]{3}{*}{2} & 0 & 1 & 1 & 1 & 1 & 1 & 1 & 1 & 0 & 1 \\
\hline & 0 & 1 & 1 & 1 & 1 & 1 & 1 & 0 & 0 & 1 \\
\hline & 0 & 1 & 1 & 1 & 1 & 0 & 0 & 1 & 1 & 1 \\
\hline \multirow[t]{6}{*}{3} & 0 & 1 & 0 & 0 & 0 & 0 & 0 & 1 & 0 & 0 \\
\hline & 0 & 1 & 0 & 1 & 1 & 1 & 0 & 1 & 1 & 0 \\
\hline & 0 & 1 & 0 & 0 & 0 & 0 & 0 & 1 & 1 & 0 \\
\hline & 0 & 1 & 0 & 1 & 0 & 0 & 1 & 1 & 1 & 0 \\
\hline & 0 & 1 & 0 & 0 & 0 & 0 & 0 & 0 & 1 & 0 \\
\hline & 0 & 1 & 0 & 0 & 0 & 0 & 0 & 0 & 0 & 0 \\
\hline \multirow[t]{8}{*}{4} & 0 & 0 & 0 & 1 & 1 & 1 & 0 & 1 & 1 & 0 \\
\hline & 0 & 0 & 0 & 1 & 0 & 0 & 0 & 1 & 1 & 0 \\
\hline & 0 & 0 & 0 & 0 & 0 & 1 & 0 & 1 & 1 & 0 \\
\hline & 0 & 0 & 1 & 1 & 1 & 1 & 0 & 1 & 1 & 0 \\
\hline & 0 & 0 & 1 & 1 & 1 & 0 & 0 & 0 & 0 & 0 \\
\hline & 0 & 0 & 0 & 1 & 0 & 0 & 0 & 0 & 1 & 0 \\
\hline & 0 & 0 & 0 & 0 & 0 & 1 & 1 & 0 & 0 & 0 \\
\hline & 0 & 0 & 0 & 1 & 1 & 0 & 0 & 0 & 0 & 0 \\
\hline \multirow[t]{2}{*}{5} & 0 & 1 & 1 & 0 & 0 & 1 & 0 & 0 & 0 & 0 \\
\hline & 0 & 1 & 0 & 0 & 1 & 0 & 1 & 1 & 0 & 0 \\
\hline
\end{tabular}




\section{Discussion}

Eight of the eleven areas with a high proportion of BME groups in their population, as measured by a threshold of 12.8 per cent or higher, had narrowing gaps, while all of the areas with gaps that were not narrowing were below this threshold. Why this should be the case involves returning both to the cases and the research literature. Looking back at the cases, five of the eight 'higher BME' localities are among the ten cases with the highest teenage pregnancy rates for 2004-2006. This accords with evidence about higher rates of teenage conceptions, teenage pregnancies and sexually transmitted infections among young people from BME backgrounds, although there is marked variation in reproductive and sexual health attitudes and outcomes across ethnic groups (French et al., 2005; Teenage Pregnancy Unit, 2005). No literature could be identified that demonstrates faster progress with these groups but by implication some factors may be important causally for this to have been happening. Possible candidates are increased awareness of the risk of infection and rising educational aspirations and achievement among young BME populations.

In a review of the last government's national teenage pregnancy strategy for England, published in 2010, there is no consideration of ethnicity (Department for Children, Schools and Families/Department of Health, 2010). This is especially surprising given that reducing teenage pregnancies was a national target and, regardless of whether 'higher BME' is having a direct, contextual or artifactual effect on narrowing the gap, it should be considered in analysing the reasons for marked differences in progress across areas with high deprivation. The presence of 'lower $\mathrm{BME}^{\prime}$ in all of the not narrowing configurations is also important since the relevant cases span a range of initial teenage conception rates, indicating that it is unlikely to be high initial rates that just happen to decline faster. In these not narrowing configurations, however, 'lower $\mathrm{BME}^{\prime}$ is necessary but not sufficient for narrowing to be absent. So 'lower $\mathrm{BME}^{\prime}$ on its own is not to be a reason for no narrowing, just as 'higher $\mathrm{BME}^{\prime}$ ' is not sufficient for narrowing.

The second narrowing configuration is a combination of three interesting conditions. 'Lower drug treatment numbers' may signal a lower prevalence of risky behaviours generally in the area. Most people in drug treatment in the UK are adults, and among teenagers underage drinking is more commonly linked with unsafe sex (McMunn and Caan, 2007). The US literature, however, identifies illicit drug use as an important risk factor for teenage pregnancy (e.g. Lohman and Billings, 2008; Cavazos-Rehg et al., 2011). Risky behaviours cluster across domains and the treatment numbers may be one 'barometer' variable in this cluster that is routinely measured and therefore available for all the local areas (Coleman, 2002; Seamark and Gray, 1998; Thornberry et al., 1997).

A 'higher proportion of under eighteens' may mean that the area is more likely to provide services for this group that divert young people from risk-taking, but this is very speculative. Since all the cases are 'lower $\mathrm{BME}^{\prime}$, it is not this condition that is explaining their younger demographic.

The third condition is surprising and counter-intuitive, since it would be expected that a higher standard of commissioning should be present rather than absent among narrowing cases. Furthermore, a lower standard of commissioning has the same counterintuitive role in one of the not narrowing configurations. Thus, a condition that represents dedicated planning to tackle high teenage conception rates appears to make things worse. 
This is a similar finding to other work that applied QCA to investigating inequalities across Spearhead areas in premature cancer mortality (Blackman et al., 2011).

Commissioning is a bureaucratic activity in the sense that it involves a strong emphasis on process: planning, coordination and monitoring compliance with 'best practice'. It entails considerable effort devoted to meetings, plans and paperwork, especially if done to excess, which may distract effort from a focus on the outcome (although it is important to note that the 'basic' descriptor for commissioning was not undemanding and no area assessed this as less than basic). The idea that being better than basic might be dysfunctional found support among many in the practitioner workshops, echoing studies of 'the new bureaucracy' that have shown how compliance with prescribed bureaucratic processes can distract from 'normal work' and learning how to match capability to outcomes (Parker and Bradley, 2004; Clarke, 2006; Travers, 2007). Achieving good or exemplary performance with processes of commissioning may entail an opportunity cost of time and resources that makes achieving the outcome less likely (Seddon, 2005, 2008).

\section{Conclusions}

QCA does not itself unravel causal mechanisms. It identifies the conditions that are present or absent when an outcome is observed and leaves explanation to the investigator and their understanding of the cases. The limitations of the data also need to be recognised, since the explanations suggested make inferences using ecological data from secondary sources and primary data based on retrospective self-assessment. The incorporation of a time dimension is an advance on many QCA studies, although the time lag of four years is short. As teenage conception rates become available, in future it will be possible to explore the effects of longer time periods.

The crisp-set QCA used in the study reduces quantitative and qualitative data to binary attributes. This is a simplification that inevitably loses much information, but, combined with a transparent approach to definitions and reasoning, goes to the essence of what matters. Furthermore, the method is not as simple as its truth tables and Boolean expressions suggest, since considerable work often has to be go into data collection and reduction, definitions and threshold judgements. QCA is not alone as a method that involves simplifying assumptions and has the advantage that these are made explicit. If there are competing theories about what causes local variation in the narrowing of teenage conception gaps, these can be tested with the same method of transparent and systematic cross-case comparison.

What QCA achieves is a basis for the qualitative consideration of complex issues based on like-with-like comparisons between cases and reduction of the data to possible causal structures and processes that generate outcomes. The focus is on actual cases rather than reified variables. This improves the robustness of case study research by using a systematic approach akin to experimental methods but, unlike much experimental research, is able to reflect real world contexts. These are contexts where outcomes often arise from combined rather than independent effects. Where single conditions exercise effects regardless of any combination with other conditions or in a limited range of such combinations, this is treated as evidence of sufficient or necessary causation rather than an effect artificially isolated by controlling for the effects of other variables. QCA is thus 
not just an alternative way of investigating the world but a challenge to the ontologies that underlie other methods that fall into either nomothetic or idiographic camps.

\section{Acknowledgement}

This article is based on a new analysis by the author using updated teenage pregnancy rate data combined with data originally collected as part of a study funded by the UK National Institute for Health Research and undertaken with David Byrne and Jonathan Wistow (see www.sdo.nihr.ac.uk/sdo2032007.html). The views expressed are those of the author and do not necessarily reflect the views of the NHS or Department of Health.

\section{References}

Allen, E., Bonell, C., Strange, V, Copas, A., Stephenson, J., Johnson, A. M. and Oalkey, A. (2007) 'Does the UK government's teenage pregnancy strategy deal with the correct risk factors? Findings from a secondary analysis of data from a randomised trial of sex education and their implications for policy', Journal of Epidemiology and Community Health, 61, 1, 20-7.

Asthana, S. and Halliday, J. (2006) What Works in Tackling Health Inequalities?, Bristol: Policy Press.

Audit Commission (2010) Healthy Balance: A Review of Public Health Performance and Spending, London: Audit Commission.

Blackman, T. (2006) Placing Health: Neighbourhood Renewal, Health Improvement and Complexity, Bristol: Policy Press.

Blackman, T., Wistow, J. and Byrne, D. (2011) 'A Qualitative Comparative Analysis of factors associated with narrowing health inequalities in England', Social Science and Medicine, 72, 12, 196574.

Bradshaw, J., Finch, N. and Miles, J. (2005) 'Deprivation and variations in teenage conceptions and abortions in England', Journal of Family Planning and Reproductive Health, 31, 1, 15-19.

Byrne, D. (1998) Complexity Theory and the Social Sciences, London: Routledge.

Byrne, D. (2011) Applying Social Science: The Role of Social Research in Politics, Policy and Practice, Bristol: Policy Press.

Cavazos-Rehg, P. A., Krauss, M. J., Spitznagel, E. L., Schootman, M., Cottler, L. B. and Bierut, L. J. (2011) 'Substance use and the risk for sexual intercourse with and without a history of teenage pregnancy among adolescent females', Journal of Studies on Alcohol and Drugs, 72, 2, 194-8.

Clarke, J. (2006), 'Scrutiny through inspection and audit', in L. Budd, J. Charlesworth and R. Paton (eds.), Making Policy Happen, London: Routledge, pp. 205-15.

Coleman, L. M. (2002) 'New opportunities for reducing the risk from teenage pregnancy - what is the evidence base for tackling risk behaviours in combination?', Health, Risk and Society, 4, 1, 77-93.

Collinge, A., Duffy, B. and Page, B. (2005) Physical Capital: Liveability in 2005, London: MORI.

Department for Children, Schools and Families/Department of Health (2010) Teenage Pregnancy Strategy: Beyond 2010, London: DCSF Publications.

Department for Communities and Local Government (2007) Common Themes: Local Strategic Partnerships and Teenage Pregnancy, London: Department for Communities and Local Government.

Department for Education and Skills (2006) Teenage Pregnancy Next Steps: Guidance for Local Authorities and Primary Care Trusts on Effective Delivery of Local Strategies, Nottingham: Department for Education and Skills.

Department of Health (1992) The Health of the Nation, London: HMSO.

Department of Health (2004) Tackling Health Inequalities: The Spearhead Group of Local Authorities and Primary Care Trusts, London: Department of Health.

Department of Health (2005a) Commissioning a Patient Led NHS, London: Department of Health. 
Department of Health (2005b) Tackling Health Inequalities: What Works, London: Department of Health.

Department of Health (2007a) Tackling Health Inequalities: 2004-06 Data and Policy Update for the 2010 National Target, London: Department of Health.

Department of Health (2007b) Commissioning Framework for Health and Well-Being, London: Department of Health.

Exworthy, M. and Powell, M. (2004) 'Big windows and little windows: implementation in the congested state', Public Administration, 82, 2, 263-81.

French, R. S., Joyce, L., Fenton, K., Kingori, P., Griffiths, C., Stone, V., Patel-Kanwal, H., Power, R. and Stephenson, J. (2005) Exploring the Attitudes and Behaviours of Bangladeshi, Indian and Jamaican Young People in Relation to Reproductive and Sexual Health, London: Teenage Pregnancy Unit.

Grofman, B. and Schneider, C. Q. (2009) 'An introduction to crisp set QCA, with a comparison to binary logistic regression', Political Research Quarterly, 62, 4, 662-72.

Lohman, B. J. and Billings, A. (2008) 'Protective and risk factors associated with adolescent boys' early sexual debut and risk sexual behaviors', Journal of Youth and Adolescence, 37, 6, 723-35.

McCulloch, A. (2001) 'Teenage childbearing in Great Britain and the spatial concentration of poverty households', Journal of Epidemiology and Community Health, 55, 1, 16-23.

McMunn, V. and Caan, W. (2007) 'Chlamydia, sexual behaviour and alcohol in young women', Nursing Standard, 21, 40, 16.

Parker, R. and Bradley, L. (2004) 'Bureaucracy or post-bureaucracy? Public sector organisations in a changing context', Asia-Pacific Journal of Public Administration, 26, 2, 197-215.

Petticrew, M. and Roberts, H. (2003) 'Evidence, hierarchies, and typologies: horses for courses', Journal of Epidemiology and Community Health, 57, 7, 527-9.

Petticrew, M., Tugwell, P., Welch, V., Ueffing, E., Kristjansson, E., Armstrong, R., Doyle, J. and Waters, E. (2009) 'Better evidence about wicked issues in tackling health inequities', Journal of Public Health, $31,3,453-6$.

Ragin, C. (2000) Fuzzy-Set Social Science, London: University of Chicago Press.

Ragin, C. (2008) User's Guide to Fuzzy-Set/Qualitative Comparative Analysis, Tucson: University of Arizona.

Rihoux, B. and Ragin, C. (eds.) (2009) Configurational Comparative Method: Qualitative Comparative Analysis and Related Techniques, Los Angeles: SAGE Publications.

Seamark, C. J. and Gray, D. J. P. (1998) 'Teenagers and risk-taking: pregnancy and smoking', British Journal of General Practice, 48, 427, 985-86.

Seddon, J. (2005) Freedom from Command and Control: A Better Way to Make the Work Work, Buckingham: Vanguard Education.

Seddon, J. (2008) Systems Thinking in the Public Sector: The Failure of the Reform Regime ... and a Manifesto for a Better Way, Axminster: Triarchy Press.

Teather, S. (2011) Minister Responds to Latest Teenage Pregnancy Statistics, http://www.education.gov.uk/ childrenandyoungpeople/healthandwellbeing/teenagepregnancy/a0074764/minister-responds-tolatest-teenage-pregnancy-statistics/ [accessed 19.12.2011].

Teenage Pregnancy Unit (2005) East London Papers Appendix A: Literature Review, London: Department for Education.

Travers, M. (2007) The New Bureaucracy: Quality Assurance and Its Critics, Bristol: Policy Press.

Thornberry, T. P., Smith, C. A. and Howard, G. L. (1997) 'Risk factors for teenage fatherhood', Journal of Marriage and Family, 59, 3, 505-22. 